\title{
Perbandingan Angka Keberhasilan Blokade Saraf Iskiadikus Pendekatan Parasakral dengan Labat Menggunakan Stimulator Saraf pada Operasi Daerah Kruris dan Pedis
}

\author{
Rika Marlina, ${ }^{1}$ Dedi Fitri Yadi, ${ }^{2}$ Tinni T. Maskoen ${ }^{2}$ \\ ${ }^{1}$ Bagian Anestesi Rumah Sakit Rawa Lumbu, ${ }^{2}$ Departemen Anestesiologi dan Terapi Intensif \\ Fakultas Kedokteran Universitas Padjadjaran/Rumah Sakit Dr. Hasan Sadikin Bandung
}

\begin{abstract}
Abstrak
Blokade saraf iskiadikus digunakan pada operasi daerah kruris dan pedis. Blokade saraf iskiadikus pendekatan Labat membutuhkan rangkaian penanda anatomis, sementara parasakral menggunakan penanda anatomis sederhana. Penelitian bertujuan membandingkan angka keberhasilan blokade saraf iskiadikus pendekatan parasakral dengan Labat. Penelitian uji acak terkendali tersamar ganda dilakukan pada 32 pasien dewasa di Rumah Sakit Dr. Hasan Sadikin Bandung dan Rumah Sakit Dr. Slamet Garut selama Desember 2014-Januari 2015. Tempat penyuntikan kelompok Labat pada $4 \mathrm{~cm}$ distal garis proyeksi tegak lurus terhadap pertengahan trokanter mayor dan spina iliaka superior posterior. Tempat penyuntikan kelompok parasakral pada $6 \mathrm{~cm}$ distal garis proyeksi antara spina iliaka superior posterior dan tuberositas iskiadikus. Penyuntikan $30 \mathrm{~mL}$ bupivakain $0,4 \%$ dilakukan bila terdapat respons motorik pada arus 0,3 mA. Perbandingan angka keberhasilan diuji dengan Uji Eksak Fisher, bermakna jika p $<0,05$. Blokade saraf iskiadikus kelompok parasakral berhasil pada 15 subjek, sedangkan Labat berhasil pada 8 subjek dengan nilai $p=0,015$. Angka keberhasilan blokade saraf iskiadikus pendekatan parasakral lebih tinggi dibanding dengan Labat menggunakan stimulator saraf pada operasi daerah kruris dan pedis.
\end{abstract}

Kata kunci: Blokade saraf iskiadikus, keberhasilan, penanda anatomis, pendekatan parasakral, pendekatan Labat

\section{Comparison of Success Rates between Parasacral Approach and Labat Approach Applied in Sciatic Nerve Block Using Nerve Stimulator in Leg and Foot Surgeries}

\begin{abstract}
Anesthesiologist uses sciatic block in leg and foot surgeries. Labat sciatic block uses a series of anatomical landmarks, while parasacral uses simple anatomical landmarks. This study compared the success rate of parasacral approach of sciatic block to Labat approach using nerve stimulator in leg and foot surgeries. A double-blind randomized controlled trial study was conducted on 32 adult patients at Dr. Hasan Sadikin General Hospital Bandung and Dr. Slamet General Hospital Garut during the period of December 2014 to January 2015. In Labat group, a line was drawn from greater trochanter to posterior superior iliac spine. Then, from the midpoint of this line, a second line was drawn perpendicularly and extended caudally to 4 $\mathrm{cm}$. The end of this line represented the needle entry. In parasacral group, a line was drawn from posterior superior iliac spine to ischial tuberosity. The needle entry was then marked on this line at $6 \mathrm{~cm}$ from the posterior superior iliac spine. Thirty $\mathrm{mL}$ of $0.4 \%$ bupivacaine was injected when a proper motor response was elicited at $0.3 \mathrm{~mA}$. Comparison of success rates were analyzed using Fisher's exact Test with $p$-value $<0.05$ considered significant. Fifteen blocks in parasacral group were successful compared to 8 blocks in Labat group, with p-value of 0.015 . The success rate of parasacral approach of sciatic block is higher than in the Labat approach when using nerve stimulator in leg and foot surgeries.
\end{abstract}

Key words: Sciatic nerve block, success, anatomical landmarks, parasacral approach, Labat approach

Korespondensi: Rika Marlina, dr., SpAn, Bagian Anestesi Rumah Sakit Rawa Lumbu, Jl. Dasa Darma Kav. 20-23 Bekasi 17116 Tlp 021-82422511, Mobile 085273121860,Email rikamr@gmail.com 


\section{Pendahuluan}

Blokade saraf perifer merupakan salah satu pilihan teknik anestesi pada penatalaksanaan operasi daerah kruris dan pedis. Kelebihan teknik blokade saraf perifer dibanding dengan anestesia umum atau anestesia neuroaksial adalah tidak memblokade simpatis yang dapat mengganggu hemodinamik dan retensi urin, mengurangi nyeri, mual, dan depresi napas pascaoperasi, pemulihan yang lebih dini, serta waktu perawatan yang lebih singkat. ${ }^{1,2}$

Blokade saraf perifer pada umumnya belum banyak dipergunakan karena membutuhkan penguasaan teknik, waktu dalam pengerjaan, dan onset dengan angka keberhasilan yang beragam. ${ }^{1,3}$ Penggunaan blokade saraf perifer dapat ditingkatkan dengan teknik yang dapat diterima dan mudah digunakan, yaitu prosedur yang sederhana dengan memakai penanda anatomis yang mudah diidentifikasi, membuat pasien merasa nyaman, dan mempunyai efek samping minimal. ${ }^{4}$

Salah satu teknik blokade saraf perifer yang digunakan untuk operasi pada daerah kruris dan pedis adalah blokade saraf iskiadikus. ${ }^{1,5,6}$ Berdasar atas alur perjalanan sarafnya, blokade sarafiskiadikus dapat dilakukan menggunakan berbagai pendekatan. ${ }^{6}$ Pendekatan posterior merupakan pendekatan yang paling banyak dipergunakan pada blokade saraf iskiadikus. ${ }^{7,8}$ Blokade saraf iskiadikus pendekatan posterior dapat dilakukan dengan posisi Sims, yaitu pendekatan Labat dan parasakral. ${ }^{1,9}$

Keberhasilan teknik blokade saraf perifer dipengaruhi oleh beberapa faktor, antara lain faktor manusia berupa pemahaman anatomi dan teknik blokade serta pengalaman; faktor teknik berupa pemilihan obat serta alat yang tepat; dan faktor pasien berupa variasi anatomi saraf perifer. ${ }^{1,3,10}$ Keberhasilan teknik blokade saraf iskiadikus membutuhkan identifikasi dengan menggunakan suatu penanda anatomis sebagai penuntun yang dapat menentukan ketepatan tempat penyuntikan., ${ }^{3,11,12}$ Pada suatu penelitian melaporkan bahwa terdapat perbedaan rentang dalam menentukan tempat penyuntikan jarum blokade saraf iskiadikus pendekatan Labat antara dokter spesialis anestesia yang berpengalaman dan dokter spesialis anestesia yang tidak berpengalaman. Blokade saraf iskiadikus pendekatan Labat membutuhkan rangkaian penanda anatomis berupa penonjolan tulang yang besar dan juga garis proyeksi yang dapat meningkatkan ketidakakuratan dalam penentuan tempat penyuntikan jarum blokade. ${ }^{13}$

Laporan dari hasil penelitian sebelumnya bahwa angka keberhasilan teknik blokade saraf iskiadikus pendekatan Labat bervariasi yaitu 52-90\%.,9 Variasi angka keberhasilan terjadi karena penentuan tempat penyuntikan jarum blokade saraf iskiadikus pendekatan Labat membutuhkan rangkaian penanda anatomis dan juga garis proyeksi yang menyebabkan hasil yang beragam dalam menemukan saraf iskiadikus. ${ }^{6}$ Penanda anatomis yang dipakai pada blokade saraf iskiadikus menggunakan pendekatan Labat merupakan garis proyeksi yang tegak lurus terhadap pertengahan garis proyeksi antara trokanter mayor dan spina iliaka superior posterior (SISP). ${ }^{5,7}$

Teknik blokade saraf iskiadikus pendekatan parasakral dilakukan terhadap struktur saraf sebelum melewati foramen iskiadikus mayor. Penanda anatomis yang dipakai pada blokade saraf iskiadikus dengan pendekatan parasakral yang merupakan garis proyeksi yang ditarik dari SISP menuju tuberositas iskiadikus. ${ }^{6,7}$ Laporan dari beberapa penelitian sebelumnya bahwa angka keberhasilan teknik blokade saraf iskiadikus memakai pendekatan parasakral mencapai 94-97\%.14,15 Blokade saraf iskiadikus mempergunakan pendekatan parasakral dilaporkan mudah dikerjakan dan dikuasai karena merupakan penanda anatomis yang sederhana. $6,14,15$

Tujuan penelitian ini yaitu membandingkan angka keberhasilan blokade saraf iskiadikus pendekatan parasakral dengan Labat memakai stimulator saraf pada operasi daerah kruris dan pedis.

\section{Subjek dan Metode}

Penelitian ini dilakukan secara eksperimental dengan uji acak yang terkendali (randomized controlled trial) dalam bentuk tersamar ganda 
(double blind) terhadap pasien berusia 18-64 tahun dengan indeks massa tubuh (IMT) 18,5$25 \mathrm{~kg} / \mathrm{m}^{2}$ dan status fisik American Society of Anesthesiologists (ASA) I dan II yang akan menjalani operasi daerah kruris dan pedis di Central Operating Theathre Rumah Sakit Dr. Hasan Sadikin Bandung dan Instalasi Bedah Sentral Rumah Sakit Dr. Slamet Garut pada periode Desember 2014 sampai dengan Januari 2015 dan menyatakan kesediaan ikut serta dalam penelitian (informed consent). Subjek yang diikutsertakan tidak termasuk dalam kriteria eksklusi, yaitu tidak kooperatif, tidak dapat mempertahankan posisi Sims, tidak dapat dinilai respons motorik pada saat blokade saraf iskiadikus dilakukan, memiliki riwayat alergi terhadap obat anestesia lokal, memiliki infeksi di daerah tempat penusukan jarum blokade saraf perifer, memiliki riwayat koagulopati, atau sedang mendapatkan terapi antikoagulan.

Penentuan jumlah sampel memakai rumus penelitian analisis komparatif kategorik dua kelompok tidak berpasangan, dan didapatkan jumlah sampel minimal adalah 32 orang pasien. Setelah mendapatkan persetujuan dari Komite Etik Penelitian Kesehatan Fakultas Kedokteran Universitas Padjadjaran/Rumah Sakit Dr. Hasan Sadikin Bandung, pasien yang termasuk dalam kriteria inklusi didata berdasarkan usia, jenis kelamin, tinggi badan, berat badan, IMT, serta status fisik ASA. Randomisasi dilakukan untuk menentukan kelompok masing-masing subjek, yaitu kelompok Labat atau parasakral. Pada kelompok masing-masing dilakukan blokade sarafiskiadikus pendekatan Labatatau parasakral sesuai dengan hasil randomisasi. Pasien tidak mengetahui pendekatan blokade saraf iskiadikus yang akan dilakukan. ${ }^{16}$

Pada kelompok labat, trokanter mayor dan SISP diidentifikasi lalu digambar garis proyeksi pertama antara 2 titik yang paling menonjol dari penanda anatomis. Kemudian, ditarik garis proyeksi kedua yang tegak lurus terhadap pertengahan garis proyeksi pertama. Tempat penyuntikan jarum berada $4 \mathrm{~cm}$ di sebelah distal garis proyeksi yang kedua. Pada kelompok parasakral, SISP dan tuberositas iskiadikus diidentifikasi lalu digambar garis proyeksi antara dua titik yang paling menonjol dari penanda-penanda anatomis tersebut. Titik penyuntikan jarum berada $6 \mathrm{~cm}$ sebelah distal garis proyeksi. ${ }^{7}$

Setelah tindakan asepsis dan antisepsis, dilakukan infiltrasi lokal memakai lidokain 1\% sebanyak $1 \mathrm{~mL}$ sebelum penyuntikan jarum blokade. Jarum blokade disuntikkan secara tegak lurus terhadap bidang sagital. Stimulasi saraf iskiadikus terlihat dari respons motorik dengan arus inisial 1,5 mA pada kedalaman 5-8 cm. Respons motorik dipertahankan sampai arus stimulasi 0,3 mA. Anestestik lokal bupivakain $0,4 \%$ sebanyak $30 \mathrm{~mL}$ disuntikkan secara intermiten sebanyak $5 \mathrm{~mL}$ setelah tes aspirasi negatif, kemudian menunggu selama 30 detik sebelum penyuntikan berikutnya. ${ }^{7}$

Pencatatan blokade sensorik serta motorik dilakukan terhadap daerah distribusi saraf iskiadikus setelah prosedur blokade selesai dalam interval waktu 5 menit selama 30 menit. Penilaian blokade sensorik dilakukan dengan skor tes pinprick 4 poin berdasarkan rentang visual analog scale (VAS). Penilaian blokade motorik menggunakan metode skala Bromage berupa skor 4 poin. Seluruh penilaian blokade dilakukan oleh peserta didik Anestesiologi dan Terapi Intensif yang tidak mengetahui tentang pendekatan blokade saraf iskiadikus yang dilakukan. ${ }^{16}$

Uji normalitas data memakai KolmogorovSmirnov. Untuk membandingkan proporsi keberhasilan pada kedua kelompok penelitian digunakan Uji Eksak Fisher. Nilai $p<0,05$ dinilai sebagai hasil yang signifikan secara statistik. Analisis data menggunakan statistical product and servise solution (SPSS) versi 15.0.

\section{Hasil}

Penelitian dilakukan terhadap 32 orang subjek penelitian di Centrral Operating Theatre (COT) Rumah Sakit Dr. Hasan Sadikin (RSHS) Bandung dan IBS Rumah Sakit Umum Dr. Slamet Garut pada periode Desember 2014 sampai dengan Januari 2015. Data subjek yang dicatat pada penelitian ini, yaitu usia, jenis kelamin, berat badan, tinggi badan, IMT, dan status fisik ASA, tidak ada perbedaan bermakna secara statistik 
Tabel 1 Karakteristik Subjek Penelitian

\begin{tabular}{|c|c|c|c|}
\hline \multirow{2}{*}{ Data Demografik } & \multicolumn{2}{|c|}{ Kelompok } & \multirow{2}{*}{ Nilai p } \\
\hline & Parasakral $(n=16)$ & Labat $(n=16)$ & \\
\hline $\begin{array}{l}\text { Usia (tahun) } \\
\text { Median } \\
\text { Rentang }\end{array}$ & $\begin{array}{c}35 \\
18-62\end{array}$ & $\begin{array}{c}48,5 \\
18-63\end{array}$ & $0,669^{*}$ \\
\hline $\begin{array}{l}\text { Jenis kelamin } \\
\text { Laki-laki } \\
\text { Perempuan }\end{array}$ & $\begin{array}{c}10 \\
6\end{array}$ & $\begin{array}{l}7 \\
9\end{array}$ & $0,288^{* *}$ \\
\hline $\begin{array}{l}\text { Berat badan }(\mathrm{kg}) \\
\text { Mean } \pm \mathrm{SD} \\
\text { Rentang }\end{array}$ & $\begin{array}{c}60,0 \pm 7,1 \\
52-78\end{array}$ & $\begin{array}{c}55,6 \pm 8,8 \\
40-69\end{array}$ & $0,130^{* * *}$ \\
\hline $\begin{array}{l}\text { Tinggi badan }(\mathrm{cm}) \\
\text { Mean } \pm \text { SD } \\
\text { Rentang }\end{array}$ & $\begin{array}{c}163,0 \pm 5,8 \\
155-175\end{array}$ & $\begin{array}{c}158,6 \pm 8,3 \\
145-170\end{array}$ & $0,097^{* * *}$ \\
\hline $\begin{array}{l}\mathrm{IMT}\left(\mathrm{kg} / \mathrm{m}^{2}\right) \\
\text { Mean } \pm \text { SD } \\
\text { Rentang }\end{array}$ & $\begin{array}{c}21,9 \pm 2,2 \\
18,6-24,9\end{array}$ & $\begin{array}{c}22,3 \pm 1,5 \\
19,2-24,8\end{array}$ & $0,549 * * *$ \\
\hline $\begin{array}{l}\text { Status fisik ASA } \\
\text { I } \\
\text { II }\end{array}$ & $\begin{array}{c}11 \\
5\end{array}$ & $\begin{array}{l}8 \\
8\end{array}$ & $0,465^{* *}$ \\
\hline
\end{tabular}

Keterangan: * Uji Mann-Whitney ** uji chi-kuadrat *** uji-t, bermakna jika p<0,05

( $\mathrm{p}>0,05$; Tabel 1).

Blokade saraf iskiadikus pada kelompok parasakral berhasil dilakukan terhadap 15 subjek dengan angka keberhasilan sebesar 93,75\%, sementara blokade saraf iskiadikus pada kelompok Labat berhasil terhadap 8 subjek dengan angka keberhasilan sebesar $50 \%$ yang berbeda bermakna secara statistik $(\mathrm{p}<0,05$; Tabel 2).

\section{Pembahasan}

Blokade saraf iskiadikus merupakan pilihan teknik anestesia untuk operasi daerah kruris dan juga pedis. Blokade saraf iskiadikus seperti blokade saraf perifer lain yang membutuhkan penanda anatomis sebagai panduan tempat

Tabel 2 Keberhasilan Blokade Saraf Iskiadikus

\begin{tabular}{lccc}
\hline Kelompok & $\begin{array}{c}\text { Tidak } \\
\text { Berhasil }\end{array}$ & Berhasil & Nilai p \\
\hline Parasakral & 1 & 15 & $0,015^{*}$ \\
Labat & 8 & 8 & \\
\hline
\end{tabular}

Keterangan: * Uji Eksak Fisher, bermakna jika p<0,05 penyuntikan jarum blokade pada teknik yang memakai stimulator saraf. Terdapat beragam penanda anatomis sesuai dengan pendekatan yang dipilih dalam melakukan blokade saraf iskiadikus. Pendekatan Labat merupakan pendekatan yang paling umum dipergunakan, sementara pendekatan parasakral merupakan pendekatan dengan letak yang lebih proksimal terhadap blokade saraf iskiadikus. Operator harus menguasai anatomi dan juga teknik yang akan dilakukan untuk mencapai keberhasilan blokade saraf perifer. ${ }^{1,10,11}$

Pada penelitian ini didapatkan bahwa teknik blokade saraf iskiadikus menggunakan pendekatan parasakral berhasil terhadap 15 subjek dengan angka keberhasilan sebesar $93,75 \%$. Semua blokade saraf iskiadikus tersebut dikerjakan oleh operator yang tidak berpengalaman mengerjakan blokade dengan pendekatan parasakral. Hasil penelitian yang telah dilakukan ini sejalan dengan penelitianpenelitian di bawah ini.

Penelitian pada tahun 1997 melaporkan angka keberhasilan blokade saraf iskiadikus pendekatan parasakral pada 30 subjek sebesar 97\%. Penelitian dilakukan oleh seorang dokter 
spesialis anestesia yang sebelumnya belum pernah mengerjakan blokade saraf iskiadikus pendekatan parasakral. ${ }^{15}$ Penelitian pada tahun 2005 melaporkan angka keberhasilan blokade saraf iskiadikus pendekatan parasakral pada 400 subjek sebesar 94\%. Penelitian dilakukan oleh dua kelompok dokter spesialis anestesi, yaitu kelompok berpengalaman dan juga tidak berpengalaman dalam mengerjakan blokade saraf iskiadikus pendekatan parasakral. Tidak terdapat perbedaan tingkat kegagalan antara dokter spesialis anestesi yang berpengalaman dan yang tidak. ${ }^{14}$

Hal yang mendukung keberhasilan blokade saraf iskiadikus pendekatan parasakral adalah penanda anatomis yang digunakan. Penanda anatomis blokade saraf iskiadikus pendekatan parasakral mudah sekali untuk diidentifikasi sehingga secara teknik menjadi sangat mudah dipelajari dan dikerjakan. ${ }^{14}$ Kelebihan blokade saraf iskiadikus menggunakan pendekatan parasakral terletak pada penanda anatomis yang sederhana dengan berpatokan garis lurus yang ditarik dari titik puncak SIPS menuju titik terbawah tuberositas iskiadikus. Garis lurus yang digunakan pada pendekatan parasakral memudahkan operator untuk menentukan bidang sagital sebagai acuan sudut dan arah penyuntikan jarum blokade yang menentukan ketepatan arah jarum mendekati lokasi saraf iskiadikus. $^{6}$

Pada penelitian ini didapatkan blokade saraf iskiadikus pendekatan Labat berhasil pada 8 subjek dengan angka keberhasilan sebesar 50\%. Sebanyak 15 tindakan blokade saraf iskiadikus pendekatan Labat dikerjakan oleh operator yang tidak berpengalaman dalam mengerjakan pendekatan tersebut. Hanya satu blokade saraf iskiadikus pendekatan Labat dikerjakan oleh operator yang berpengalaman mengerjakan pendekatan tersebut.

Hasil penelitian yang telah dilakukan sejalan dengan hasil penelitian pada tahun 1993 yang meneliti angka keberhasilan blokade saraf iskiadikus pendekatan Labat pada 20 subjek. Angka keberhasilan blokade saraf iskiadikus pendekatan labat didapatkan sebesar 52\%. Semua blokade saraf iskiadikus dikerjakan oleh operator yang tidak berpengalaman dalam mengerjakan pendekatan Labat. ${ }^{4}$

Pengetahuan merupakan hal yang sangat berperan penting dalam pengerjaan blokade saraf perifer yang berdampak terhadap angka keberhasilan. ${ }^{4}$ Penelitian pada tahun 1992 melaporkan angka keberhasilan blokade saraf iskiadikus pendekatan Labat pada 20 subjek sebesar $90 \%$ yang dikerjakan oleh operator yang berpengalaman dalam mengerjakan pendekatan tersebut. ${ }^{9}$

Penelitian pada tahun 2003 melaporkan variasi yang lebih besar dalam menentukan tempat penyuntikan jarum blokade antara 15 dokter spesialis anestesia yang berpengalaman serta 22 dokter spesialis anestesia yang tidak berpengalaman dalam mengerjakan blokade saraf iskiadikus pendekatan Labat. Terdapat perbedaan rentang tempat penyuntikan jarum blokade, pada kelompok yang berpengalaman sebesar 37-40 mm dan pada kelompok yang tidak berpengalaman sebesar 67-85 mm. Blokade saraf iskiadikus pendekatan Labat membutuhkan rangkaian penanda anatomis berupa penonjolan tulang yang besar dan juga garis proyeksi yang dapat meningkatkan ketidakakuratan dalam penentuan tempat penyuntikan jarum blokade. ${ }^{13}$

Teknik blokade saraf iskiadikus pendekatan Labat membutuhkan serangkaian penanda anatomis serta garis proyeksi dengan tempat penyuntikan jarum yang berupa titik tunggal. Tempat penyuntikan jarum blokade berupa titik tunggal pada bidang gluteus yang bundar dapat memungkinkan terjadinya kesalahan penempatan sudut serta arah jarum blokade. Hal tersebut dapat mengurangi ketepatan arah jarum mendekati lokasi saraf iskiadikus dalam radius 360 derajat. $^{6}$

Setelah jarum blokade saraf disuntikkan, penempatan ujung jarum sedekat-dekatnya terhadap struktur saraf akan bergantung pada respons motorik yang ditimbulkan stimulator saraf. ${ }^{17,18}$ Faktor yang memengaruhi teknik stimulasi saraf pada blokade saraf perifer adalah struktur saraf dan kemungkinan variasi anatomi pada daerah penyuntikan. ${ }^{3}$ Penelitianpenelitian melaporkan variasi anatomi saraf iskiadikus pada daerah otot piriformis yang mencapai $10,7-23,5 \%$ yang dilakukan pada 
kadaver. Variasi anatomi berupa pemisahan saraf tibialis dan juga peroneal komunis tidak terjadi pada fosa popliteal, melainkan pada saat memasuki regio gluteal pada daerah otot piriformis. ${ }^{19}$

Tempat penyuntikan jarum blokade saraf iskiadikus pendekatan posterior pada bidang gluteal merupakan daerah otot piriformis. Pemisahan saraf tibial dan peroneal komunis terjadi pada fosa popliteal dengan variasi anatomi, yaitu pemisahan dapat terjadi pada daerah otot piriformis. Pemisahan saraf tibial dan peroneal komunis akan memengaruhi penyebaran anestetik lokal yang disuntikkan. Tempat penyuntikan yang semakin distal mengakibatkan penyebaran obat anestesi lokal tidak mencakupi saraf tibial dan juga peroneal komunis, terutama apabila pemisahan antara kedua saraf tersebut terjadi pada daerah yang lebih proksimal seperti otot piriformis. ${ }^{6,19,20}$

Kelebihan teknik blokade saraf iskiadikus pendekatan parasakral adalah blokade yang dilakukan lebih proksimal pada daerah otot piriformis, sementara blokade saraf iskiadikus pendekatan Labat dilakukan pada daerah yang terdapat kemungkinan variasi anatomi saraf iskiadikus terhadap otot piriformis sehingga dapat memengaruhi penyebaran obat anestesi lokal dalam mencakupi saraf tibial dan juga peroneal komunis. Hal ini dapat memengaruhi keberhasilan blokade saraf iskiadikus.,

Pendekatan parasakral memiliki beberapa faktor yang berperanan dalam menentukan keberhasilan blokade saraf iskiadikus dengan menggunakan stimulator saraf.

\section{Simpulan}

Angka keberhasilan blokade saraf iskiadikus pendekatan parasakral lebih tinggi dibanding dengan blokade saraf iskiadikus pendekatan Labat menggunakan stimulator saraf pada operasi daerah kruris dan pedis.

\section{Daftar Pustaka}

1. Tureanu L, Ganapathy S, Nader A. Sciatic nerve block and ankle block. Dalam: Benzon HT, Raja SN, Liu SS, Fishman
SM, Cohen SP, penyunting. Essentials of pain medicine. Edisi ke-3. Philadelphia: Elsevier; 2011. hlm. 607-16.

2. Stein BE, Srikumaran U, Tan EW, Freehill MT, Wilckens JH. Lower-extremity peripheral nerve blocks in the perioperative pain management of orthopaedic patients. J Bone Joint Surg Am. 2012;94(22):e167.

3. Reichman EF, Meer J, Seth N. Regional nerve blocks. Dalam: Reichman EF, penyunting. Emergency medicine procedures. Edisi ke-2. New York: McGraw-Hill; 2013. hlm. 802-4.

4. Chang PC, Lang SA, Yip RW. Reevaluation of the sciatic nerve block. Reg Anesth. 1993;18(1):18-23.

5. Hadzic A, Vlodka JD. Sciatic block: posterior approach. Dalam: Hadzic A, penyunting. Peripheral nerve blocks: principles and practice. Edisi ke-1. New York: McGrawHill; 2004. hlm. 234-44.

6. Bollini CA, Moreno M. Sciatic nerve block. Tech Reg Anesth Pain Manag. 2006;10:163-72.

7. Gaertner E, Fouché E, Choquet O, Hadzic A, Vloka JD. Sciatic nerve block. Dalam: Hadzic A, penyunting. Textbook of regional anesthesia and acute pain management. Edisi ke-1. New York: McGraw-Hill; 2007. hlm. 517-31.

8. Rest C. Sciatic nerve blocks. Dalam: Chelly JE, penyunting. Peripheral nerve blocks: a color atlas. Edisi ke-3. Philadelphia: Lippincott Williams \& Wilkins; 2009. hlm. 112-6.

9. Tran D, Clemente A, Finlayson RJ. A review of approaches and techniques for lower extremity nerve blocks. Can J Anesth. 2007;54(11):922-34.

10. Madison SJ, Illfeld BM. Peripheral nerve blocks. Dalam: Butterworth JF, Mackey DC, Wasnick JD, penyunting. Morgan \& Mikhail's clinical anesthesiology. Edisi ke-5. New York: McGraw-Hill Education; 2014. hlm. 976-7.

11. Shorten G. Introduction. Dalam: Harmon D, penyunting. Peripheral nerve bocks and peri-operative pain relief. Edisi ke-2. Philadelphia: Elsevier; 2011. hlm. 1-5. 
12. Chan VWS, Nova H, Abbas S, McCartney CJL, Perlas A, Xu DQ. Ultrasound examination and localization of the sciatic nerve. Anesthesiology. 2006;104(2):309-14.

13. Grant SA, Breslin DS, MacLeod DB, Demeyts D, Martin G, D'Ercole F, dkk. Variability in determination of point of needle insertion in peripheral nerve blocks: a comparison of experienced and inexperienced anaesthetists. Anaesthesia. 2003;58:684711.

14. Ripart J, Cuvillon P, Nouvellon E, Gaertner E, Eledjam J-J. Parasacral approach to block the sciatic nerve: a 400-case survey. Reg Anesth Pain Med. 2005;30(2):193-7.

15. Ben-Ari AY, Joshi R, Uskova A, Chelly JE. Ultrasound localization of the sacral plexus using a parasacral approach. Anesth Analg. 2009;108(6):1977-80.

16. Abrahams MS, Aziz MF, Fu RF, Horn JL. Ultrasound guidance compared with electrical neurostimulation for peripheral nerve block: a systematic review and meta-analysis of randomized controlled trials. Br J Anaesth. 2009;102(3):408-17.

17. Denny NM, Harrop-Griffiths W. Location, location, location! Ultrasound imaging in regional anaesthesia. $\mathrm{Br} \mathrm{J}$ Anaesth. 2005;94(1):1-3.

18. Chin KJ, Chan V. Ultrasound-guided peripheral nerve blockade. Curr Opin Anaesthesiol. 2008;21(5):624-31.

19. Smoll NR. Variations of the piriformis and sciatic nerve with clinical consequence: a review. Clin Anaesth. 2010 Jan;23(1):8-17.

20. Sukhani R, Nader A, Candido KD, Doty R Jr, Benzon HT, Yaghmour E, dkk. Nerve stimulator-assisted evoked motor response predicts the latency and success of a single-injection sciatic block. Anesth Analg. 2004;99(2):584-8. 